Article

\title{
Managing Social Networks in Online-Native Newsrooms: When Less Means More
}

\author{
Antonio Mendez, Bella Palomo * and Agustin Rivera \\ Department of Journalism, University of Malaga, 29018 Malaga, Spain; E-Mails: antmendez@uma.es (A.M.), \\ bellapalomo@uma.es (B.P.), agustinrivera@uma.es (A.R.) \\ * Corresponding author
}

Submitted: 15 December 2019 | Accepted: 1 February 2020 | Published: 16 April 2020

\begin{abstract}
During the last few years online-only media have been explored as an alternative to mainstream media. The development of this new media model coincides in time with an increase in dependence on social networks. Online media editors estimate that one third of their visits proceed from Facebook, a figure that obliges them to create specific strategies to ensure their company's reputation and growth in the 2.0 field. The aim of this article is to assess what motivates Spanish digitalnative newspapers to act on social networks, analyse their internal view of these channels, and describe their strategies for managing their relationship with audiences. Based on a qualitative and longitudinal approach, we conducted in-depth interviews with the social media editors of the most relevant digital-native newspapers in Spain-El Confidencial, Eldiario.es, El Español and El HuffPost-during 2017 and 2019, in order to trace the evolution of their professional routines. These social media editors consider that although digital-native newsrooms are smaller than traditional ones, they are more agile in reacting to metrics. Our results also confirm that Instagram is generating great expectations, and the new paywall system is affecting the way audiences are understood.
\end{abstract}

\section{Keywords}

audience; media business; new media; newspaper; online-native newsroom; social media; social networks

\section{Issue}

This article is part of the issue "Digital Native News Media: Trends and Challenges" edited by Ramón Salaverría (University of Navarra, Spain).

(C) 2020 by the authors; licensee Cogitatio (Lisbon, Portugal). This article is licensed under a Creative Commons Attribution 4.0 International License (CC BY).

\section{Introduction}

For several years The Huffington Post and BuzzFeed have headed the world ranking of media that generate the most user engagement (Poell \& Van Dijck, 2014) and have been classified as the 'most social' publishers on the web. In 2013, Buzzfeed produced 7,500 posts a month for Facebook and generated nearly 16 million interactions in the form of likes, comments and shares ("Who are the most social," 2013). According to Storyclash, in June 2017 Huffington Post US's interactions had risen to 28.7 million, and in BuzzFeed's case to 25.4 million. In Europe the year 2013 saw the appearance of De Correspondent, following a crowdfunding campaign that in only eight days managed to collect $€ 1$ million
(Harbers, 2016). These publications form part of a new typology of mass medium, the digital-native media-new actors that coexist with legacy media and technological platforms, configuring a hybrid media system (Chadwick, 2013). This new scenario combines "the best practices of traditional journalism-fairness, accuracy, storytelling, deep investigations - with the best tools available to the digital world-speed, transparency, and, above all, engagement" (Huffington, 2013).

Their spread has coincided with the crisis and weakness of the conventional media system. Thus, while the staff at traditional newsrooms was cut by $25 \%$ between 2008 and 2018 in the US, in that same period employment in digital-native newsrooms almost doubled, rising from 7,400 to 13,500 (Geiger, 2019). In Spain the 
map of digital-native media rose from representing 9.1\% of all digital media in 2005 to $35.1 \%$ in 2018. In that year 3,065 active digital media were identified, of which 1,077 were digital-natives (Salaverría, Martínez-Costa, \& Breiner, 2018). These figures have resulted in the development of digital-native media acquiring positive connotations, and to their being explored as an alternative to mainstream media. This has been a cause of optimism for the profession and the new generations of journalists, as they see new opportunities for growth and professional survival in the activities of these online-native media.

In general, digital-born news media are smaller than legacy media in terms of their reach, resources, and revenues, while at the same time they have smaller newsrooms, leaner organizations, and lower distribution costs (Nicholls, Shabbir, \& Nielsen, 2016). This smaller volume together with their innate digital mentality has speeded up the implantation of editorial innovation, experimentation with forms, specialization of content and the use of alternative sources, all of which has favoured the heterogeneity of existing models. Another characteristic of the most relevant digital-native newspapers is that their emergence is usually associated with values. They affirm their commitment to creating a different, freer and better-informed society by means of a regenerated journalism (Harlow \& Salaverría, 2016) that is independent, rigorous and responsible, and publishes exclusive, striking and high-quality investigations, all of which connects them to publics disappointed with conventional media. Moreover, their routines are committed to the practice of accountable journalism, recognized by numerous awards, such as the five Pulitzer Prizes won by Propublica. In Spain, exclusive investigations by El Confidencial and Eldiario.es resulted in the resignation of two ministers from the new government (Negredo, Vara, Amoedo, \& Moreno, 2019).

Proximity to their audiences is another of their distinctive features, which is why from the start they have placed their trust in social media, as mentioned above. In this sense, their participation on social media has awoken a similar optimism, not only because of the traffic they obtain, but because, treated appropriately, users are transformed into subscribers (Southern, 2019). The key, as some reports note, resides in quality rather than clicks (Nicholls, Shabbir, Graves, \& Nielsen, 2018).

The main consequence of this intermediation, according to the Reuters Institute Digital News Report 2019 , is that only $29 \%$ of the audience prefers to access news via the web or publishers' applications, although percentages differ greatly between countries. In the specific case of Spain, the figure falls to $20 \%$, while $53 \%$ choose social media as sources of news (Nicholls, Fletcher, Kalogeropoulos, \& Nielsen, 2019). This context, combined with the broad census of online-native media that emerges from previous studies and their capacity for innovation (García-Aviles, Carvajal-Prieto, de Lara-González, \& Arias-Robles, 2018), justify an exploratory analysis that addresses how these companies manage social media. The novelty of this article lies in its analysis of how social media management has evolved at four digital native media over two years. It provides the inside view of social media editors on adapting to the challenges of a permanently changing environment influenced by complexity and uncertainty theories (Wilczek, 2019).

\subsection{The Context of the Spanish Media System}

The present structure of the media groups in Spain began to take shape after the arrival of democracy 40 years ago. With the disappearance of the dictatorship and on the basis of the freedom of expression guaranteed by the Constitution of 1978, new newspapers emerged, the ownership of others changed hands, and publishing groups began to develop that would finally become multimedia groups. In the Spanish mass media sector there is a predominance of companies that publish printed newspapers, the majority with a regional or provincial character, and there are no yellow newspapers or evening editions (Salaverría, Díaz-Noci, López, \& Palomo, 2005). More recently, the peculiarities of the Spanish media system, with its high concentration of companies and vigorous online press, together with the country's political instability during the last years have favoured the spread and consolidation of the most relevant digitalnative newspapers, especially following the fall in sales of the printed media. In this sense, the circulation of the ten main newspapers decreased by 92,000 copies in 2018 (Negredo et al., 2019). With respect to media consumption in Spain, television is the medium most used for obtaining news $(91 \%)$, while social media are the second option with $77 \%$, figures that are above the European average (Palacio, 2018, p. 68).

\section{Literature Review}

From the perspective of the academy, most scientific production related to digital-born media has focused on comparing their practice with that of legacy media. The search for recognition and legitimacy in the sector has given rise to a combination of conservative and transformative strategies (Stringer, 2018). Thus, after analysing BuzzFeed's reporting during the 2015 and 2017 UK general election campaigns, Thomas and Cushion (2019) concluded that the coverage provided by this popular digitalnative media platform had evolved and was approaching the logic of institutional news media. Nonetheless, Painter, Kristiansen, and Schäfer (2018) did observe differences in the news coverage related to climate change, where more selective approaches were applied to attract new audience segments. Different news consumption patterns between legacy and digital-native news brands have also been observed (Arrese \& Kaufmann, 2016).

Case studies of different countries have made it possible to recognize diverse funding models, distribution strategies and editorial priorities, and to draw up a ba- 
sic typology of digital-born media: domestic for-profit players, whose reach, resources, and digital revenues are similar to those of the legacy news media, thus making them possible competitors; domestic non-profit players, which depend on donations and complement the legacy media; and international for-profit players, which prioritize global expansion via the system of 'growth-firstrevenues-later' (Nicholls et al., 2016, p. 36).

The development of this new media model coincides in time with an increase in the dependence on social networks. The prominence achieved by content proceeding from these spaces has given rise to a wide conceptual debate on what constitutes news (Canter, 2018), and has also been the axis of some investigations that have detected how the extensive use of social networks by digital-native media has not only influenced the shape of agenda setting (Bane, 2019), but also the creation of a different kind of reporting, employing a youthful tone, and covering taboo topics (Nicholls et al., 2016, p. 32). In this respect, the use made of Twitter during electoral periods has also been analysed, with the conclusion that the levels of production and engagement of legacy media are still far higher (Majó, Zhao, Nurse, \& Nielsen, 2017).

This article is related to others that focus on journalists' perceptions of the changes in professional routines and newsroom culture (Ryfe, 2009; Zeller \& Hermida, 2015). In general, the culture of professionalism in the newsroom is resilient and resistant to change. Nevertheless, the activity journalists develop on social media tends to be more technology driven, brand inspired, entrepreneurial and interactive (Järventie-Thesleff, Moisander, \& Villi, 2014). This proximity influences the newsroom strategies employed, since earlier studies show that subjective writing style or polar sentiments expressed in the title of an article are positively associated with number of shares (Khuntia, Sun, \& Yim, 2016). Some social media editors accentuate emotional and surprising story elements in posts, while also accepting the logic of algorithms to obtain social impact (Lischka, 2018). This constant and initially disruptive adaptation of routines has been normalized, in spite of entailing a dislocation of news and a loss of power (Broersma \& Eldridge, 2019).

In spite of the close relation that digital-native media has maintained with social media since their emergence, there are no studies on how their journalists perceive their activities on social media, how they evaluate engagement generated beyond the website, what their limits are and the point to which they are willing to cede editorial control as they depend on non-proprietary platforms (Westlund \& Ekström, 2018). To gain a better understanding of how this intermediation is being managed and the relevance of this activity for the medium, our main research questions are:

RQ1: What differences do social media managers perceive between social media activity in legacy media and digital-native media?
RQ2: What are the motives of digital-native media for acting on social media?

RQ3: How have their strategies evolved over time?

\section{Methods}

The methodology applied in this research to explore how digital-native media manage social media and to analyse their routines has a qualitative character (Patton, 2014). In-depth interviews provide a more complete and, in general, a more critical perspective for understanding the decisions taken by the media that affect their routines, as well as the causes that motivate them. A total of nine semi-structured, in-depth interviews were conducted with social media managers from four of the most relevant digital-native media in Spain. The same number of interviews was applied by Zeller and Hermida (2015) to obtain the personal opinions and attitudes of senior online news managers and leading online journalists in Canada. Attention was paid to their different characteristics to ensure that different models would be represented and to develop a comparative perspective. We will now justify the selected case studies. El Confidencial, which had been active for 18 years in 2019, is the digitalnative medium with the largest audience in Spain-it has 16.5 million unique users according to Comscore. It has the most staff, 155 workers, and an advertising turnover that reached $€ 18$ million in 2018. El Español, which emerged in 2015, has a similar sized audience and was the first digital newspaper launched in Spain thanks to crowdfunding. A total of 5,624 investors contributed $€ 3,606,000$ in a campaign that lasted for one and a half months and broke the world record in the journalistic sector (Del Arco, Yunquera, \& Pérez, 2016). El HuffPost is an international player, founded in 2005 in the US with the name The Huffington Post. It operates in different languages and countries, mainly drawing on blogs and viral content. Its Spanish edition was launched in 2012 in coownership with Prisa (50\%), the multimedia group that owns El País. These distinctive characteristics, together with a small newsroom made up of 22 people, justify its selection for inclusion in this investigation. The year 2012 also saw the emergence of Eldiario.es, which defends independent journalism and whose success is based on a mixed model of financing. Currently, 34,000 subscribers contribute $33 \%$ of its revenues.

Various earlier investigations approached digitalborn media by applying the case study method to understand the activity developed by peripheral actors in journalism (Hermida \& Young, 2019) or the evolution of the role of some digital native companies that began as online content aggregators or distributing viral content, to then move closer to hard news content ( $\mathrm{Wu}, 2016)$. Recently, Vos and Thomas (2018) noted the absence of longitudinal studies that analyse changes beyond a single event or isolated organization. The importance of this research resides in the fact of its being a longitudi- 
Table 1. List of interviewees.

\begin{tabular}{lll}
\hline Organization & Name and position & Year of interview \\
\hline El Confidencial & Jose Manuel Rodriguez, social media editor & 2017 \\
& Eva Moreno, social media manager & 2019 \\
Eldiario.es & Ander Oliden, frontpage and social media manager & $2017-2019$ \\
El Español & Angela Bonachera, social media editor & 2017 \\
& Patricia Morales, social media manager & 2017 \\
El HuffPost & Ana Delgado, social media manager \& video manager & 2019 \\
\hline
\end{tabular}

nal study that considers how social media management has evolved at four media over two years. This approach is justified by the instability of this activity, which becomes apparent when the journalists interviewed are observed (Table 1), since two years on from the first interview only two remained at the medium to which they were affiliated. Diachronic studies applied to journalism that include industry insights provided by interviews with reporters make it possible for tendencies to be analysed (Knowles, Phillips, \& Lidberg, 2017); such studies have also been applied in a specific form to webbased communication and social media (Williamson \& Parolin, 2013). Concretely, this investigation was inspired by Chua and Westlund (2019); their case study method, involving two rounds of semi-structured, in-depth interviews over two and a half years, was also applied.

The first round of interviews was conducted in early 2017 , in person and in the newsrooms of the newspapers. Several pre-tests were conducted, and the results were discussed with the group coders and the project leader. In 2019 , the instrument was updated with the incorporation of new challenges that had emerged into the questionnaire and the interviews were conducted between August and October that year by telephone, a combination that had also been successfully implemented in previous studies (Sehl, Cornia, Graves, \& Nielsen, 2019). The Likert scale questionnaire was added in the final round to evaluate how the relevance accorded to social media at the medium had evolved: 5 indicated that the social media department worked in a radically different way; 4 that there had been slight improvements; 3 stability; 2 that the department had reduced its tasks; and 1 that the department had lost prominence and even personnel. In total, 500 minutes of data were recorded. All the interviews together with the notes were uploaded to the Atlas.ti application in order to categorize the content and enrich the qualitative results.

\section{Results}

\subsection{Their Priority: Activity on Social Media}

The search for social impact is usually inherent in the history of online-native media (Nicholls et al., 2016, p. 33). When Pedro J. Ramirez announced the launch of the new online newspaper he would be editing, El Español, it already had social networks inscribed in its DNA, as he announced that its characteristics included being universal, independent, combative, plural, innovative, balanced, intelligent, and Twitter-enthusiastic (Del Arco et al., 2016). In fact, prior to its launch, the medium's Facebook account already had 20,500 followers, with 114,000 on Twitter.

For the social media managers of the Spanish onlinenative media analysed, these data demonstrate an unprecedented degree of social support, and in comparison with traditional media they consider their newsrooms to be more aware and better prepared to face the challenges of social media. They are also more agile when it comes to reacting to metrics, because their task does not end with the publication of their work online; 'direct selling' of their news items to the audience is also necessary. To achieve this goal they have the necessary skill and a positive attitude towards participatory environments is more widespread; although their staffs are smaller than those of the most relevant traditional media, they are more open to social experimentation. Thus, at El Español they have achieved a situation where the news writers are their own community managers. The managers at Eldiario.es and El HuffPost express themselves in similar terms, as their staffs are experts at working on social media and from the start both media have included relevant tweeters and bloggers amongst their collaborators. This reorientation of routines coincides with the alteration of news choreography; at Eldiario.es they confirm that their priority is to transmit a news item to a social network-even before elaborating the front page of the online publication-since it is the user's first window.

Further data confirms this commitment to, and success on, social media. Although the most relevant traditional media, like El País or El Mundo, have built up a bigger community on social media, none of their managers is active in these environments. A practice that runs contrary to the social reputation achieved by the editors of online-native media, like Pedro J. Ramirez at El Español, who, with 533,300 followers on Twitter, exceeds the number of followers of the main account of the medium he edits; or Ignacio Escolar, whose 966,200 followers approaches the figure reached by Eldiario.es. The latter has used the hashtag \#EscolarResponde to 
strengthen the connection with his audience and attend to questions from social network users.

Guillermo Rodríguez, editor of El HuffPost, admits that this dependence on social media also gives rise to more errors. These result from a spontaneity that makes online-native media more closely resemble the radio than the traditional press:

The difference between online-native media and the traditional press is vast in every respect. Proximity to current affairs and the constant need to be publishing what is happening at the moment... An online medium is much more similar to a radio than to a newspaper because we live off breaking news, analysis in the heat of the moment. (Guillermo Rodríguez, personal communication)

This proximity to the audio-visual sector has enabled El Español and El Confidencial to integrate the video department in the social media department.

The proximity to their audiences of these media and their need to distinguish themselves from the news offer of the legacy media has also boosted the introduction of new sections where subscribers can publish articles, and private communication channels for sending in confidential tips, data and documents in a secure and anonymous way. Filtra.la, the portal for citizen complaints that forms part of the Associated Whistleblowing Press, is the platform used by Eldiario.es, while El Confidencial provides a secure mailbox powered by GlobaLeaks, and also relies on the encryption provided by WhatsApp and Signal.

But why do online-native media consider social media to be a priority? In 2017 their reasons included obtaining audience for the website, increasing traffic to increase publicity revenues, and spreading the brand image. For a medium that only operates online, a large part of its growth, the projection of its values and its social impact, all depend on social media. As José Manuel Rodríguez observes:

El Confidencial is active on social media basically so that those who are unaware of its existence can get to know about it. Moreover, social media serve to capture readers because there are four essential steps in the strategy for audience development: attraction, retention, fostering loyalty and politicization. On social media we take care of attraction, that is, managing to attract people to the El Confidencial brand. (José Manuel Rodríguez, personal communication)

Guillermo Rodríguez's statements also reflected an obsession with traffic in 2017:

We have to increase our number of followers on all social media, to test all of them at the same time; and if we see that it isn't working, to forget about them without any problem. Above all, our strategy consists in paying a lot of attention to Facebook: it's God. (Guillermo Rodríguez, personal communication)

In 2017 the editor of El HuffPost declared that social media were the main entrance portal to the website for readers $-50 \%$ of total traffic-while at present this doesn't exceed 28\%. In 2019 direct circulation and rebound proceeding from El País accounted for $55 \%$ of the total, which is why they are promoting the brand more, which means paying greater attention to messages on Twitter and Instagram.

El Español also wanted to obtain greater visibility in 2017, and to achieve this they were not averse to tweeting content from other media. They were already publishing comic strips on Instagram, photos from their best reportages and were building stories. They now seek to establish a more personalized connection with the reader, giving priority to quality over quantity.

This motive has also run up against the negative side of participation (Quandt, 2018). In 2017 Eldiario.es was already warning about the exhaustion of some journalists, who had noticed a transformation of the environment and were constantly having to deal with messages that were more aggressive and insistent.

\subsection{Evolution of Strategies}

The longitudinal study of the tasks and strategies developed by social media managers at online-native media in 2017 and 2019 made it possible to detect that intuition took precedence over planning, and that there had been significant changes in their routines. These basically materialized in three aspects: 1 ) increasing their presence on social media, extensively and intensively; 2 ) capturing new subscribers; 3 ) and creating internal protocols to protect themselves against disinformation. On a Likert scale, all the interviewees rated this transformation above 4, cataloguing it as intense, and even radical, as they told us at El Español.

\subsubsection{From Facebook to Instagram}

From the organizational point of view, what stands out is the polyvalence of the members of the newsrooms studied. At El HuffPost seventeen journalists work on social media; four people are exclusively dedicated to Facebook and two to Instagram. Their editor believes that part of their success is due to the fact that there is neither unity of criteria nor a single discourse; each journalist applies their own style. At Eldiario.es two people are exclusively dedicated to social media, one more than two years ago. The seven section managers also contribute to the medium's activity on social media, although they must combine this with updating the portal and breaking news. El Español and El Confidencial both assign three people per day to managing social media.

Twitter and Facebook are the two social media that receive the most attention from the media analysed, 
since they provide between $14 \%$ and $30 \%$ of their global traffic, figures that have fallen in comparison with 2017. At that time Facebook Live was a novelty and live transmissions became one of the goals of the participation managers consulted, in order to increase their audience and seek new business options. At present Zuckerberg's company continues to provide $80 \%$ of the readers proceeding from social media. However, their interest has shifted to Instagram, which is giving rise to greater expectations and is the big challenge for the future.

Instagram traffic to the media websites is still very limited, but it allows them to experiment, approach a younger market niche and increase their reach. The editor of El HuffPost, Guillermo Rodríguez, envisaged reaching 100,000 followers by the end of 2019-in 2017 they had 2,000-and he is certain of its economic benefits:

Instagram is not only a good platform for younger users to get to know you, but also nowadays it is the platform with the biggest and best advertising outlet for sponsored content and stories. It is what advertisers are increasingly demanding. They want their advertising and their branded content to appear on Instagram channels. (Guillermo Rodríguez, personal communication)

Determining which is the fourth most relevant network does not produce such a homogeneous reply. For Eldiario.es it is Telegram. Since 2015 it has used this mobile instant messaging application, and it is currently the Spanish medium with the highest number of subscribers, 25,836 . Linkedin is the fourth most important network for El Confidencial; El Español chooses WhatsApp, and El HuffPost opts for Youtube, although the rest of the media analysed do not consider it to be a social network.

What they do agree on is the social network that causes them the most upsets: Facebook. Its changes of algorithm and its opacity have made it into a friend-enemy. At El Confidencial each day they wonder where Facebook is going to place its hand: "On your head to push you under, on your shoulder to support you or in your pocket to take away your money?" Rodríguez says that one can have all three sensations on the same day. For all the media analysed, the change of algorithm in 2018 is the most remembered and caused the greatest concern. This was because Facebook prioritized the content of friends and relatives, causing the closure of social-media-dependent outlets and millennial press such us Buzzfeed Spain or Eslang (Negredo et al., 2019). In face of the resulting confusion and sharp decline in traffic, which exceeded $40 \%$, the reaction of the media analysed consisted in diversifying topics to reach new audiences, launching more viral videos and testing other alternative tools like Google Discover or Flipboard. "We tried everything," Guillermo Rodríguez explained at El Huffpost:

Publishing at different times, publishing more, less, different approaches, and in the end we understood that the golden age of Facebook wasn't going to return....But that change of algorithm also inoculated us to work on developing audiences in a much more integral way. (Guillermo Rodríguez, personal communication)

According to El Español, news related to politics, nutrition and the sciences works very well for them on Facebook, and they never publish on Friday evenings because the community is usually disconnected from Internet. In spite of that, they consider Facebook to be a capricious medium, which sometimes forces them to pay as much for increasing traffic as for seeking a public that they do not reach organically.

They consider that Facebook operates a very strict policy on content publication that has also affected their posts, eliminating some news items related to sex or violence. Due to these peculiarities at El Huffpost the traffic team is in charge of publishing content on Facebook, as they are experts at content and audience optimization. Eldiario.es prefers to elaborate specific content for this social network and they avoid overreacting when facing a change of algorithm: "Some media react by sharing news items about missing persons, creating alarm, but that is not the course we want to follow," Oliden concludes.

\subsubsection{Increasing Frequency of Publication}

A comparative study of the attention paid to Facebook and Twitter during the two years analysed confirms that there has been an increase in the volume of messages published on each network. El Confidencial set itself the goal of publishing 30 posts per day and 100 tweets in 2017. El Español applied a more aggressive strategy on Facebook with 80 posts and 96 tweets. El HuffPost did not include social media publication amongst its goals. In 2019 El Confidencial had risen to 96 posts and 144 tweets per day. Each month El Español publishes some 1,500 posts on Facebook and 2,500 tweets. El HuffPost has regularized its activity, with an average of 40 posts and 170 tweets a day. Only the figures for Eldiario.es remain steady, with 35 posts and 90 tweets published each day.

In addition to increasing the frequency of publication, the social media editor at El Confidencial adds that other recent novelties consist in dedicating more time to getting to know national and international tendencies, monitoring the activity of competitors and intensifying communication with the SEO team to develop joint strategies, such as employing different styles of language to address their followers depending on the channel.

Google Analytics, Chartbeat, Parse.ly, CrowdTangle and Buzzsumo are some of the monitoring tools employed that influence editorial decisions related to the production and distribution of content, although at El HuffPost they prefer to rely on the internal tools provided by Facebook and Twitter. This relevance of metrics responds to a global tendency known as 'analytics-driven 
journalism' (Moyo, Mare, \& Matsilele, 2019) that makes it possible to evaluate the impact, scope and relevance of news content.

The social media manager at El Español, Ana Delgado, states that the audience's importance is far greater than it was in 2017, and they must keep track of what its current interests are and what news generates more engagement:

Previously a social media department's work was simply unidirectional, it was limited to distributing content. Now it is bidirectional, it gathers reactions and establishes conversations. At El Español we have learned that readers continue to be the most important pivot of our work and everything must be arranged around them. It is essential for us to base our work on data in order to identify and understand our audience. This is a prior step to implanting a microsystem of subscriptions....The role of readers as protagonists is now greater than ever, which means we must understand them much, much better. (Ana Delgado, personal communication)

The expectations generated in the journalistic sector by the potential of active audiences are largely based on the belief that interactivity creates loyalty (Sundet \& Ytreberg, 2009). Krumsvik (2013) identified a typology of strategies for user involvement via social media for the news industry: the deliberation strategy, the donation strategy, the distribution strategy, and the data gathering strategy. The media analysed have prioritized the third strategy, sharing content, but they also appeal to the audience to express its opinion and take part in surveys, polls or quizzes, in order for it to perceive that the medium does not only sell content and thus achieve a high recurrence rate. Conversation improves engagement.

\subsubsection{Adapting to Paywalls}

The social media managers at online-native media state that they are better prepared for the paradigm change in accessing the online press and do not think that there will be a fall in the number of messages they produce for social media, even though the complete content is not diffused. According to Eva Moreno, at El Confidencial, "Our work will have to develop in keeping with 'paywall' strategies and, as a result, the social media department will also have to contribute value to the product we distribute" (Eva Moreno, personal communication). In September 2019 her medium launched ECPremium, a payment model that makes possible advance access to political and economic news items, designed especially for managers and institutions that must take short-term decisions based on such news.

Since its foundation in 2012 , it has been a priority at Eldiario.es to obtain revenues through subscribers' quotas in order to increase the medium's independence. In
2019 this community consisted of 34,000 subscribers, who browse without any advertising, can access exclusive content before its open publication, and whose comments appear highlighted. With the arrival of new formulas for accessing content in the Spanish media system, Ander Oliden announced that Eldiario.es would never build a paywall around content:

It would be desirable for subscription models to help eliminate content from the media that has an exclusively viral focus, often far removed from the values that those media claim to defend. This change should not entail abandoning the use of social media. (Ander Oliden, personal communication)

El Español already had 12,000 subscribers in 2017. For that reason its social media manager believes that his department will continue to have an equally relevant function, but its work will be much more qualitative than quantitative in character. Its regular tasks will include the possibility of transforming readers into subscribers.

At El Huffpost they are not considering a paywall in their business model, but they are convinced that to share a closed news story it is not necessary to be subscribed to the medium, because users talk on social media about news items without needing to read more than the headline that appears in a tweet.

The digital native media coincide in believing that payment models will be standardized in the short term, and that the movement of big traditional newspapers like El País or La Vanguardia will mark out the path for the rest. Additionally, over the next three years they foresee the implantation of publication models that are more automated, native content will be created for networks, user experience will be improved and the importance of clickbait will be reduced.

\subsubsection{The Challenge of Disinformation}

In the interviews conducted in 2017 the social media managers made no mention of disinformation. At that time the main goal was to increase traffic, without taking into account the collateral damage that would be caused by the proliferation of fake content and the need to create verification teams (Adair, Stencel, Clabby, \& $\mathrm{Li}, 2019)$, in order to counter the phenomenon and reduce the widespread scepticism amongst readers who were questioning all types of content selection (Fletcher \& Nielsen, 2018).

At present, the spread of disinformation has resulted in greater precautions being taken by the social media managers in all the newsrooms analysed. The manager at El Confidencial says they are more careful about the news they publish and that there is greater contact between the social media team and the newsroom for joint questioning and verification. They believe that such mutual feedback is essential, and extreme caution is taken when dealing with political news. 
At El Huffpost they are convinced that fake content has a greater impact than people realize, but they maintain a constructive attitude and think that, essentially, being permanently on the alert helps improve the situation. To speed up the process they prioritize official sources, videos and photographs about which there is absolute certainty that they were taken at the time and place stated. Ana Delgado, social media manager and video manager at El Español, agrees that priority should be given to primary sources, such as the institutions, politicians or other well-known figures:

The concept of disinformation is highly debatable. Now conversations are much quicker and this phenomenon has become more evident via social media. But I believe that our work as journalists continues to consist, as always, in verifying information wherever it proceeds from. Journalists cannot publish news items that proceed from a social network unless that source is a primary one. (Ana Delgado, personal communication)

Finally, outsourcing verification is another of the strategies implemented. In January 2019 Eldiario.es signed a collaboration agreement with Maldita.es, a medium that specializes in countering disinformation. The goal was not to free the newsroom from searching for unfounded rumours, but instead to strengthen its commitment by putting a brake on fake news items, especially in an electoral year marked by great political instability. The contract consists in Maldita.es publishing content in Eldiario.es that exposes unfounded rumours related to immigration or human rights. Furthermore, they provide them with political statements subjected to factchecking techniques that Eldiario.es publishes first, while publication on the Maldita.es website is embargoed for 24 hours. This collaboration has also made it possible to verify electoral debates in real time, and such vigilance helps the medium to function as a counter-power and resolve the distrust journalists feel towards politicians (Humanes, Martínez-Nicolás, \& Saperas, 2013).

\section{Conclusions}

In the new information ecosystem, social media and online-native media occupy a privileged position. Both involve activity that has been $100 \%$ digital since their origin. This has favoured their connection and the presence in these newsrooms of a symbiotic attitude, open to the different existing formulas of participation. Collaboration is considered to be the sole formula for surviving in the temporalities of the media ecology (Dodds, 2019). In response to the first question posed, this investigation describes a scenario that distances the journalists at digitalnative media from the digital divide found in traditional newsrooms, moving them closer to the profiles defined by Hedman and Djerf-Pierre (2013) as 'pragmatic conformists' and 'enthusiastic activists.' In comparison with legacy media, social media managers at digital-native media consider that their staffs, in a state of permanent transition obliging them to work faster and more efficiently, are better prepared for reacting to the challenges presented by social media, which is why they feel closer to the audio-visual sector than to the traditional press.

Aware of the risks that derive from working with platforms like Facebook, whose change of algorithm directly affects their content production and its scope, this instability does not cast a shadow over their motives for participating actively on such platforms, which are concentrated on developing traffic, business and the brand. With its longitudinal approach, this article provides evidence that, two years on from the first round of interviews, there have been substantial changes in the routines of the participatory sections of digital-native media, although the search for traffic continues to be the main reason for their activity on social media. It is essential to be involved in the share-out of advertising, which is why their strategies are centred on seeking new audience targets, increasing their activity on social media, and constantly monitoring tendencies and the behaviour of users and competitors. The great difference is that now they are not as concerned about the quantity as about the quality of the readers they attract, in case the latter are potential subscribers. Users are not just numbers, they must by captured with names and surnames. To achieve that goal the tendency is towards forming specialized teams according to the social network, which construct more personalized messages adapted to the particular channel. It is surprising to find that while the effort dedicated to social networks has increased and been rationalized, the traffic proceeding from those spaces has fallen.

Although the digital native media analysed have distinctive features, in general similarities were found in how they manage social media and they are optimistic as they perceive that their activity will grow. Although uncertainty continues to form part of their routines and their strategies are guided by the technique of trial and error, they see more opportunities than disadvantages in their relation with social media. This relation has matured because they act more prudently and collaboratively with the newsroom to avoid spreading disinformation, while the stage of obsession with Facebook has also become shorter. This reshaping of their dependence, predicted by Ekström and Westlund (2019), has resulted in the field of experimentation now being situated in Instagram, and they are confident that audio-visual content will be profitable in the future. Paradoxically, they believe that this future will be determined by the movements made by the most relevant traditional newspapers, although the audience will continue to be the axis of change. The tendency of activity on social media will consist in spreading quality content, subscription tools and winning the trust of the young public.

With respect to the limitations of the study, an analysis of four cases is not a basis for generalization, but this exploration of their activity could be extended to the rest 
of the media that form part of the census drawn up by Salaverría et al. (2018). Additionally, we suggest pursuing the qualitative approaches that make it possible to know how legacy media journalists and audiences perceive the work developed by the online-native media, identify the causes of the fall in social media traffic, and even suggest prospective studies that make it possible to determine whether online-native media will end up forming part of legacy media in the future.

\section{Acknowledgments}

This work was supported by the project 'News, Networks and User in the Hybrid Media System: Disinformation, Transparency and Cybersecurity in Journalism Practice,' and the Department of Journalism at the University of Malaga.

\section{Conflict of Interests}

The authors declare no conflict of interests.

\section{References}

Adair, B., Stencel, M., Clabby, C., \& Li, C. (2019). The human touch in automated fact-cheking. Paper presented at the Computation + Journalism Symposium, Miami, FL.

Arrese, A., \& Kaufmann, J. (2016). Legacy and native news brands online: Do they show different news consumption patters? International Journal on Media Management, 18(2), 75-97.

Bane, K. C. (2019). Tweeting the agenda: How print and alternative web-only news organizations use Twitter as a source. Journalism Practice, 13(2), 191-205.

Broersma, M., \& Eldridge, S. A. (2019). Journalism and social media: Redistribution of power? Media and Communication, 7(1), 193-197.

Canter, L. (2018). It's not all cat videos: Moving beyond legacy media and tackling the challenges of mapping news values on digital native websites. Digital Journalism, 6(8), 1101-1112.

Chadwick, A. (2013). The hybrid media system. Oxford: Oxford University Press.

Chua, S., \& Westlund, O. (2019). Audience-centric engagement, collaboration culture and platform counterbalancing: A longitudinal study of ongoing sensemaking of emerging technologies. Media and Communication, 7(1), 153-165.

Del Arco, M. A., Yunquera, J., \& Pérez, F. (2016). The first one hundred days of El Español: Analysis of the structure and contents of an online newspaper during its beginnings. Revista Latina de Comunicación Social, 71, 527-551.

Dodds, T. (2019). Reporting with WhatsApp: Mobile chat applications' impact on journalistic practices. Digital Journalism, 7(6), 725-745.

Ekström, M., \& Westlund, O. (2019). The dislocation of news journalism: A conceptual framework for the study of epistemologies of digital journalism. Media and Communication, 7(1), 259-270.

Fletcher, R., \& Nielsen, R. K. (2018). Generalised scepticism: How people navigate news on social media. Information, Communication \& Society, 22(12), 1751-1769.

García-Aviles, J., Carvajal-Prieto, M., de Lara-González, A., \& Arias-Robles, F. (2018). Developing an index of media innovation in a national market: The case of Spain. Journalism Studies, 19(1), 25-42.

Geiger, A. W. (2019, September 11). Key findings about the online news landscape in America. Pew Research Center. Retrieved from https://www.pewresearch. org/fact-tank/2019/09/11/key-findings-about-theonline-news-landscape-in-america

Harbers, F. (2016). Time to engage: De Correspondent's redefinition of journalistic quality. Digital Journalism, 4(4), 494-511.

Harlow, S., \& Salaverría, R. (2016). Regenerating journalism: Exploring the 'alternativeness' and 'digital-ness' of online-native media in Latin America. Digital Journalism, 4(8), 1001-1019.

Hedman, U., \& Djerf-Pierre, M. (2013). The social journalist: Embracing the social media life or creating a new digital divide? Digital Journalism, 1(3), 368-385.

Hermida, A., \& Young, M. L. (2019). From peripheral to integral? A digital-born journalism not for profit in a time of crisis. Media and Communication, 7(4), 92-102.

Huffington, A. (2013, October 14). Bezos, Heraclitus and the hybrid future of journalism. Huffington Post. Retrieved from https://www.huffpost.com/ entry/future-of-journalism_b_3756207

Humanes, M. L., Martínez-Nicolás, M., \& Saperas, E. (2013). Political journalism in Spain: Practices, roles and attitudes. Estudios sobre el Mensaje Periodístico, 19(2), 715-731.

Järventie-Thesleff, R., Moisander, J., \& Villi, M. (2014). The strategic challenge of continuous change in multiplatform media organizations: A strategy-as-practice perspective. International Journal on Media Management, 16(3/4), 123-138.

Khuntia, J., Sun, H., \& Yim, D. (2016). Sharing news through social networks. International Journal of Media Management, 18(1), 59-74.

Knowles, S., Phillips, G., \& Lidberg, J. (2017). Reporting the global financial crisis. Journalism Studies, 18(3), 322-340.

Krumsvik, A. H. (2013). Towards a typology of strategies for user involvement. In M. Friedrichsen \& W. MühlBenninghaus (Eds.), Handbook of social media management (pp. 657-670). Berlin: Springer.

Lischka, J. (2018). Logics in social media news making: How social media editors marry the Facebook logic with journalistic standards. Journalism. https://doi. org/10.1177/1464884918788472

Majó, S., Zhao, J., Nurse, J., \& Nielsen, K. (2017). Digital- 
born and legacy news media on Twitter during the UK general election. Oxford: Reuters Institute for the Study of Journalism.

Moyo, D., Mare, A., \& Matsilele, T. (2019). Analyticsdriven journalism? Editorial metrics and the reconfiguration of online news production practices in African newsrooms. Digital Journalism, 7(4), 490-506.

Negredo, S., Vara, A., Amoedo, A., \& Moreno, E. (2019). Spain. In N. Nicholls, R. Fletcher, A. Kalogeropoulos, \& K. Nielsen (Eds.), Digital news report 2019 (pp. 82-83). Oxford: Reuters Institute for the Study of Journalism.

Nicholls, N., Fletcher, R., Kalogeropoulos, A., \& Nielsen, K. (2019). Digital news report 2019. Oxford: Reuters Institute for the Study of Journalism

Nicholls, T., Shabbir, N., Graves, L., \& Nielsen, K. (2018). Coming of age: Developments in digital-born news media in Europe. Oxford: Reuters Institute for the Study of Journalism.

Nicholls, T., Shabbir, N., \& Nielsen, K. (2016). Digital-born news media in Europe. Oxford: Reuters Institute for the Study of Journalism.

Painter, J., Kristiansen, S., \& Schäfer, M. K. (2018). How 'digital-born' media cover climate change in comparison to legacy media: A case study of the COP 21 summit in Paris. Global Environmental Change, 48, 1-10.

Palacio, L. (Ed.). (2018). Informe anual de la profesión periodistica. Madrid: APM.

Patton, M. Q. (2014). Qualitative research and evaluation methods integrating theory and practice. Thousand Oaks, CA: Sage Publications.

Poell, T., \& Van Dijck, J. (2014). Social media and journalistic independence. In J. Bennet \& N. Strange (Eds.), Media independence: Working with freedom or working for free? (pp. 182-201). London: Routledge.

Quandt, T. (2018). Dark participation. Media and Communication, 6(4), 36-48.

Ryfe, D. (2009). Broader and deeper: A study of newsroom culture in a time of change. Journalism, 10(2), 197-216.

Salaverría, R., Díaz-Noci, J., López, X., \& Palomo, B. (2005). Spain: Multimedia richness and variety of business models. In R. Van Der Wurff \& E. Lauf (Eds.), Print and online newspapers in Europe (pp. 231-243). Amsterdam: Het Spinhuis Publishers.

Salaverría, R., Martínez-Costa, M. P., \& Breiner, J. (2018).
Map of digital news media at Spain in 2018: Quantitative analysis. Revista Latina de Comunicación Social, 73, 1034-1053.

Sehl, A., Cornia, A., Graves, L., \& Nielsen, K. (2019). Newsroom integration as an organizational challenge. Journalism Studies, 20(9), 1238-1259.

Southern, L. (2019, November 28). How social media is powering The Economist's subscription growth. Digiday. Retrieved from https://digiday.com/ media/how-social-media-is-powering-theeconomists-subscription-growth

Stringer, P. (2018). Finding a place in the journalistic field. Journalism Studies, 19(13), 1991-2000.

Sundet, V. S., \& Ytreberg, E. (2009). Working notions of active audiences: Further research on the active participant in convergent media industries. Convergence, 15(4), 383-390.

Thomas, R., \& Cushion, S. (2019). Towards an institutional news logic of digital native news media? A case study of BuzzFeed's reporting during the 2015 and 2017 UK general election campaigns. Digital Journalism, 7(10), 1328-1345. https://doi.org/10.1080/ 21670811.2019.1661262

Vos, T., \& Thomas, R. (2018). The discursive (re)construction of journalism's gatekeeping role. Journalism Practice, 13(4), 396-412.

Westlund, O., \& Ekström, M. (2018). News and participation through and beyond proprietary platforms in an age of social media. Media and Communication, 6(4), $1-10$.

Who are the most social publishers on the web? (2013, October 3). The Guardian. Retrieved from https:// www.theguardian.com/news/datablog/2013/oct/ 03/who-are-most-social-publishers-web-buzzfeed

Wilczek, B. (2019). Complexity, uncertainty and change in news organizations. International Journal of Media Management, 21(2), 88-129.

Williamson, W., \& Parolin, B. (2013). Web 2.0 and social media growth in planning practice: A longitudinal study. Planning Practice \& Research, 28(5), 544-562.

$\mathrm{Wu}, \mathrm{L}$. (2016). Did you get the buzz? Are digital native media becoming mainstream? \#ISOJ, 6(1), 131-150.

Zeller, F., \& Hermida, A. (2015). When tradition meets immediacy and interaction: The integration of social media in journalists' everyday practices. Sur le Journalism, 4(1), 106-119.

\section{About the Authors}

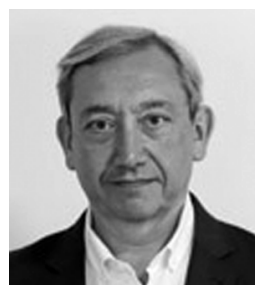

Antonio Mendez is Associated Professor at the University of Málaga (Spain). He holds a PhD in Journalism. His main research interests are local journalism, broadcast journalism, the influence of new technologies on news narratives, and the credibility of media. He has a long and relevant career as a journalist. At present Mendez is Editor-in-Chief of Malaga Hoy newspaper. 


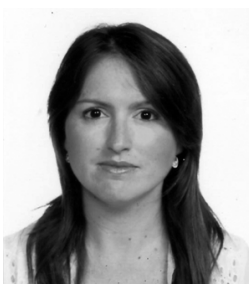

Bella Palomo is Full Professor and Head of Journalism Department at the University of Malaga (Spain). Palomo has focused her line of research on digital journalism during the last two decades. She has been Visiting Scholar at the Universities of Washington, Rutgers, Miami (US), and Federal de Bahia (Brazil). She is leading the project 'News, Networks and User in the Hybrid Media System: Disinformation, Transparency and Cybersecurity in Journalism Practice.'

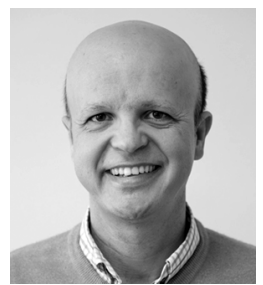

Agustin Rivera is Associated Professor at the School of Communication of the University of Málaga (Spain). He holds a PhD in Journalism. His main research interests are political journalism, international coverages, the value of opinion journalism, and professional routines. He has a long career as a foreign correspondent in 14 countries. His professional activity has been developed in the newspapers El Mundo and El Confiencial. 